\title{
P02.157. Dose-response of spinal manipulation for low back pain: outside care outcomes from a randomized clinical trial
}

\author{
D Vavrek*, M Haas, D Peterson \\ From International Research Congress on Integrative Medicine and Health 2012 \\ Portland, Oregon, USA. 15-18 May 2012
}

\section{Purpose}

To assess amounts of outside care amongst participants who participated in a randomized clinical dose trial assessing Spinal Manipulative Therapy (SMT) for chronic low back pain (cLBP).

\section{Methods}

Four hundred participants with cLBP were randomized to 4 doses $(\mathrm{n}=100 /$ group). Participants were seen three times per week for six weeks, receiving $0,6,12$, or 18 sessions of SMT, and a light massage control on visits without manipulation. Data were collected until 52 weeks after randomization. Outside care outcomes included prescription and non-prescription use, and treatments outside of the study including the following healthcare providers: chiropractor, primary care physician, surgeon, neurologist, psychiatrist, naturopath/ homeopath, nurse practitioner, acupuncturist, physical therapist / occupational therapist, or massage therapist. Preliminary analysis used the chi-square test or Fisher's exact test of categorized data as appropriate.

\section{Results}

Abstinence from prescription use for prevention of cLBP, within the past four weeks, was greater than $75 \%$ of participants using none at any time point. The abstinence from non-prescription medication, within the last four weeks, was greatest in the 18 SMT visit group from week 6 through week 39 follow-up time points with the greatest incidence of non-use at $54 \%$ at week six. Seeking care from a chiropractor during the follow-up phase did not differ between groups at any time point with average chiropractor seeking behavior across all four groups reaching

University of Western States, Portland, USA a maximum at 52 weeks of $10.6 \%$. Differences between groups seeking outside care from a massage therapist were observed at 18 and 52 weeks, with more SMT associated with less massage care, but this was not consistent across all time points.

\section{Conclusion}

Preliminary analysis of outside care shows that care was balanced across all four dose groups during treatment phases including use of prescription and treatment visits to non-study medical providers and classes. Results from adjusted models will be presented.

Published: 12 June 2012

doi:10.1186/1472-6882-12-S1-P213

Cite this article as: Vavrek et al:: P02.157. Dose-response of spinal manipulation for low back pain: outside care outcomes from a randomized clinical trial. BMC Complementary and Alternative Medicine 2012 12(Suppl 1):P213.

Submit your next manuscript to BioMed Central and take full advantage of:

- Convenient online submission

- Thorough peer review

- No space constraints or color figure charges

- Immediate publication on acceptance

- Inclusion in PubMed, CAS, Scopus and Google Scholar

- Research which is freely available for redistribution
(C) 2012 Vavrek et al; licensee BioMed Central Ltd. This is an Open Access article distributed under the terms of the Creative Commons Attribution License (http://creativecommons.org/licenses/by/2.0), which permits unrestricted use, distribution, and reproduction in any medium, provided the original work is properly cited. 